\title{
Fuzzy Tsukamoto Implementation on Internet of Things to Control Flooding
}

\author{
Andi Riansyah ${ }^{1}$, Dedy Kurniadi ${ }^{2}$, Saebani ${ }^{3}$ \\ ${ }_{1}^{1}$ Universitas Islam Sultan Agung/Jurusan Teknik Informatika \\ Jl. Raya Kaligawe KM., e-mail: andi@unissula.ac.id \\ ${ }^{2} U$ niversitas Islam Sultan Agung/Jurusan Teknik Informatika \\ Jl. Raya Kaligawe KM., e-mail: ddy.kurniadi@unissula.ac.id \\ ${ }^{3}$ Universitas Islam Sultan Agung/Jurusan Teknik Informatika \\ Jl. Raya Kaligawe KM., e-mail: saebani@unissula.ac.id
}

\section{ARTICLE INFO}

Article history:

Received 11 September 2019

Received in revised form 02 January 2020

Accepted 03 January 2020

Available online 31 January 2020

\begin{abstract}
A Flooding is a disaster that often occurs in the Semarang area, especially on J1. Raya Kaligawe. Flooding can occur due to the ineffectiveness of the pump work in a water impregnation pool. The impact of the floods is detrimental to students because with the flooding it can interfere with teaching and learning activities and studying student activities when on campus. At Sultan Agung Islamic University, Semarang has a water impregnation pool that is still manually controlled. By using Fuzzy Tsukamoto as artificial intelligence on Internet of Things technology, we can carry out intelligent control systems in water absorption pool pumps in realtime, so as to prevent and reduce human error that causes flooding. In principle, the Internet of Things works using a microcontroller, one of the microcontrollers that can be used, namely Wemos D1 mini. Wemos D1 mini is connected with an ultrasonic sensor to measure water level in a water infiltration pond, air temperature and air humidity sensor to detect rain.
\end{abstract}

Keywords: Floods, Fuzzy Tsukamoto, Internet of Things

\section{Pendahuluan}

Banjir merupakan salah satu bencana alam yang kerap terjadi di berbagai daerah di Indonesia [1]. Debit air yang mengalir pada suatu saluran drainase atau kolam peresapan air yang melebihi diatas kapasitas pengal daya tampung dan resapnya akan menyebabkan terjadinya banjir. Gangguan pada saluran drainase bisa menjadi penyebab munculnya genangan air pada lahan yang biasanya kering seperti pada lahan permukiman atau pusat kota yang nantinya genangan tersebut membesar dan menjadi banjir [2]. Menurut BNPB pada tahun 2013 banjir mempunyai dampak fisik maupun non-fisik, dampak fisik bisa dilihat dari kerusakan suatu area yang terkena banjir. Sedangkan dampak non-fisik bisa dirasakan dari kerugian tidak langsung, dampak non-fisik yang diderita oleh masyarakat tetapi juga kerugian non-fisik seperti diliburkan sekolah karena area sekolah tidak dapat diakses karena banjir, meningkatnya harga barang kebutuhan pokok yang disebabkan jalur distribusi susah diakses karena banjir, dan trauma dan penyakit yang diderita paska banjar bahkan terkadang sampai ada yang meninggal dunia [2].

Jalan Raya Kaligawe merupakan salah satu wilayah yang ada di Kota Semarang yang kerap dilanda banjir ketika misim hujan tiba. Pergurunan tinggi Universita Islam Sultan Agung (UNISSULA) beralamat di JL. Raya Kaligawe, dimana pada musim hujan 2017 mengalami 
banjir di beberapa area kampus. Dampak negatif yang ditimbulkanya diantaranya mengangu kegiatan belajar mengajar dan menganggu lalu lintas di Universitas Islam Sultan Agung Semarang. Di UNISSULA terdapat beberapa kolam peresapan air yang digunakan untuk mengantisipasai luapan air, namun kolam peresapan air ini masih dikontrol secara manual dengan tenaga manusia. Mengkontrol kolam peresapan air secara manual memungkinkan terjadinya human error seperti terlambat mengaktifkan pompa, mengaktifkan pompa yang tidak sesuai (seharusnya aktif hanya satu pompa tapi yang aktif tiga pompa atau sebaliknya) sehingga mengakibatkan penggunaan daya listrik yang tidak sesuai dengan kebutuhan. Maka dari itu dibutuhkan alat yang dapat mengkontrol otomatis kolam peresapan air.

Berdasarkan uraian diatas peneliti akan membuat sistem untuk memonitoring dan mengkontrol kolam peresapan air dengan menerapkan kecerdassan buatan Fuzzy Tsukamoto pada Internet of Things (IoT) di UNISSULA, sehingga pompa yang ada pada kolam peresapan air dapat dikontrol secara otomatis dan data ketinggian air dapat di pantau secara tepat waktu.

\section{Research Method}

2.1 Internet Of Things (IoT)

Perkembangan keilmuan Internet of Things sangat menjanjikan di era industri 4.0 untuk mengoptimalkan kehidupan berdasarkan sistem kontrol, kendali, dan otomasi cerdas dengan perangkat-perangkat fisik yang bekerjasama dan terhubung melalui jaringan internet [4]. Dengan menggunakan internet of things akan memudahkan aktifiktas manusia dalam keseharianya misalnya kita dapat memonitoring suhu ruangan dengan menggunkan hp atau komputer. Interaksi diantara manusia berkurang karena kemampuan pertukaran informasi pada di sebagian waktu antara komputer dan peralatan elektronik, hal ini menjadikan meningkat dengan berbagai fasilitas dan layanan internet karena tuntutan pengguna [5]. Arsitekur IoT model [6] ditunjukan pada gambar 1

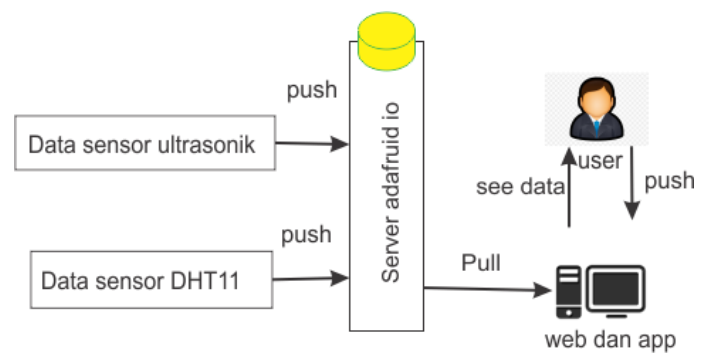

Gambar 1. IoT Architectural Model

Pada gambar 1 menunjukan proses alur data IoT. Dimana data sensor ultrasonik yang digunakan untuk memonitor tingkat ketinggian air paa kolam peresapan serta data sensor DHT11 untuk mengukur suhu dan kelembaban udara yang digunakan mendeteksi kondisi cuaca akan dikirimkan ke cloud computing Adafruid IO menggunakan protokol MQTT (Message Queuing Telemetry Transport). MQTT merupakan protokol komunikasi publish/subscribe yang sederhana, ringan dan didesain untuk alat yang memiliki kemampuan terbatas. MQTT mempunyai kemampuan untuk dapat mendukung sebuah perangkat IoT. MQTT pada prinsipnya mempunyai pusat pertukaran informasi antara subscriber dan publiser yaitu MQTT broker [9]. Publiser sendiri adalah pengirim data misalnya sensor sedangkan Subscriber adalah penerima data misalnya manusia [9]. Deasin rangkaian sensor DHT11 yang dihubungkan dengan Wemos D1 MINI dan pini yang digunakan pada Wemos D1 MINI agar terhubung dengan sensor DHT11 yang sudah dikalibrasi sebagai pengukur suhu dan kelembaban udara untuk menentukan kondisi cuaca ditunjukan pada gambar 2. 


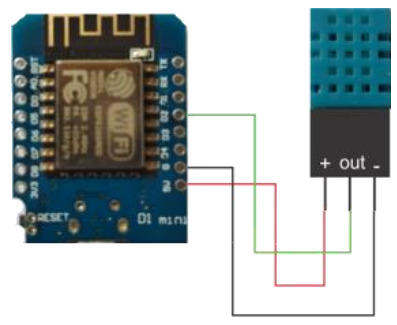

Gambar 2. Rangkaian sensor DHT11 dengan Wemos D1 MINI

Selanjutnya untuk desain rangkaian sensor Ultrasonik yang dihubungkan dengan Wemos D1 MINI dan pin yang digunakan pada Wemos D1 MINI agar terhubung dengan sensor Ultrasonik dan dikalibrasi untuk mengukur tingkat ketinggian air yang ada pada kolam peresapan air, ditunjukan pada gambar 3 .

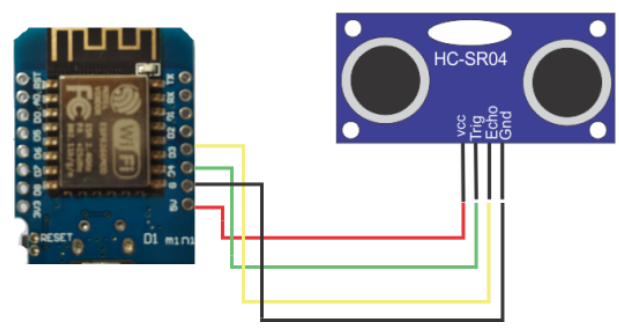

Gambar 3 Rangkaian sensor Ultrasonik dengan Wemos D1 MINI

Dan yang terakhir rangkaian pengendali jumalah dan kecepatan pompa, penegndali L298 yang dihubungkan dengan Wemos D1 MINI dan pin yang digunakan pada Wemos D1 MINI agar terhubung dengan sensor pengendali pompa L298 untuk mengendalikan jumlah dan kecepatan pompa air sesuai dengan kondisi tingkat ketinggian air di kolam peresapan dan kondisi cuaca ditunjukan pada gambar 4.

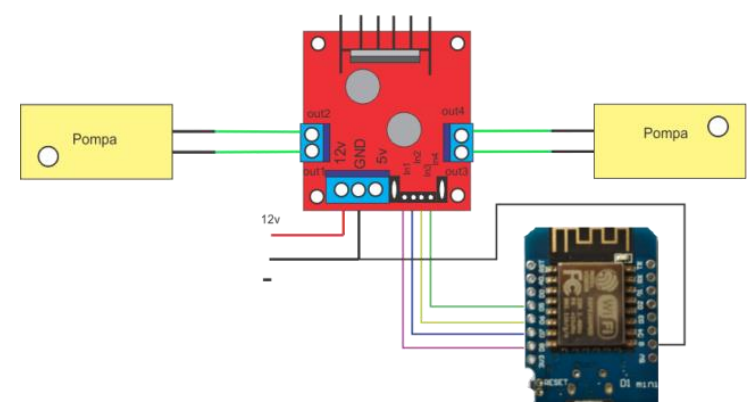

Gambar 4. Rangkaian pengendali pompa L298 dengan Wemos D1 MINI

\subsection{Logika Fuzzy Tsukamoto}

Logika Fuzzy merupakan salah satu cabang dari ilmu komputer yang mempelajari tentang nilai kebenaran yang bernilai banyak dan sistem yang sangat rumit pemecahannya[7]. Berbeda dengan nilai kebenaran pada logika tradisional dirancang untuk mengontrol keluaran tunggal yang bernilai 0 (salah) atau 1(benar) yang tidak saling berhubungan. Logika Fuzzy mempunyai nilai kebenaran real dalam selang 0 sampai dengan 1 . Pembuatan keputusan didapat dari pengurangan jumlah nilai besar menjadi nilai derajat keanggotaan yang berawal dari pemrosesan awal sejumlah nilai besar variabel ada sistem fuzzy[7].

Dalam logika fuzzy terdapat fungsi kenaggotaan untuk menentukan nilai derajat keanggotaan dari variabel. Fungsi keanggotaan yang digunakan adalah suatu kurva segitiga yang

Fuzzy Tsukamoto Implementation on the Internet of Things to control flooding (Andi Riansyah) 
menunjukan pemetaan dari setiap titik input data kedalam suattu nilai derajat keanggotaanya yang memiliki interval 0 sampi dengan 1. Salah satu cara yang dapat digunakan untuk mendapatkan nilai keanggotaanya adalah dengan melalui pendekatan fungsi dan aturan tertentu [8].

Metode yang digunakan pada penelitian ini adalah fuzzy Tsukamoto. Variabel yang digunakan adalah kelembapan udara yag diperoleh dari sensor DHT11 dan jarak air diperoleh dari sensor ultrasonik. Untuk output berupa nilai range 0-100. Proses metode ini ditunjukan pada gambar 5.

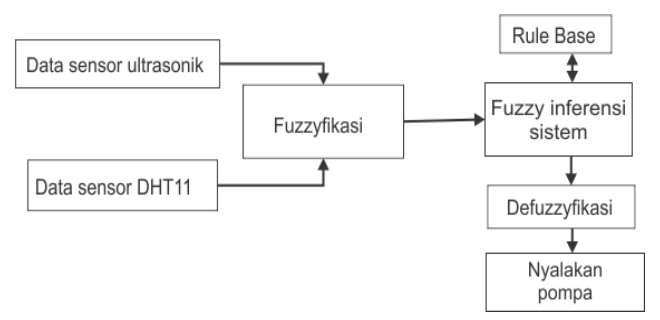

Gambar 5. Tahapan Fuzzy Tsukamoto

Tahap pertama yaitu Fuzzyfikasi, proses diman variabel input diubah menjadi nilai crisp menjadi yang kemudian nilai ini menjadi variabel linguistik menggunakan fungsi keanggotaan [10]. Selanjutnya masuk pada tahap pembentukan basis pengetahuan fuzzy (rule base dalam bentuk IF...THEN). Input ini kemudian dikirim ke basis pengetahuan yang berisi $\mathrm{n}$ aturan fuzzy dalam bentuk IF-THEN. Secara umum bentuk model Fuzzy Tsukamoto adalah IF X and Y THEN A dimana X dan Y adalah himpunan Fuzzy. Apabila jumlah aturan lebih dari satu, maka akan dilakukan agregasi dari semua aturan. Yang ketiga adalah mesin inferensi, yaitu proses dengan menggunakan fungsi implikasi MIN untuk mendapatkan nilai $\alpha$-predikat tiap-tiap rule $(\alpha 1, \alpha 2, \alpha 3, \ldots \alpha$ n). Kemudian masing-masing nilai $\alpha$-predikat ini digunakan untuk menghitung keluaran hasil inferensi secara tegas (crisp) masing-masing rule (z1, z2, z3, ..zn) [10]. Dan tahap yang terakhir adalah Defuzzyfikasi, dengan menggunakan rata-rata. Output sistem didapat berupa nilai crips dari hasil agregasi yang dilakukan pada saat Defuzzy.

\section{Hasil dan Analisa}

Implementasi merupakan tahapan yang dilakukan untuk menerapkan sistem yang telah dibangun sesuai dengan perancangan sistem yang telah bangun. Berikut ini tampilan untuk pengguna berbasis web yang ditunjukan pada gmabr 6 . user interface dari adafruid io yang telah dibuwat:

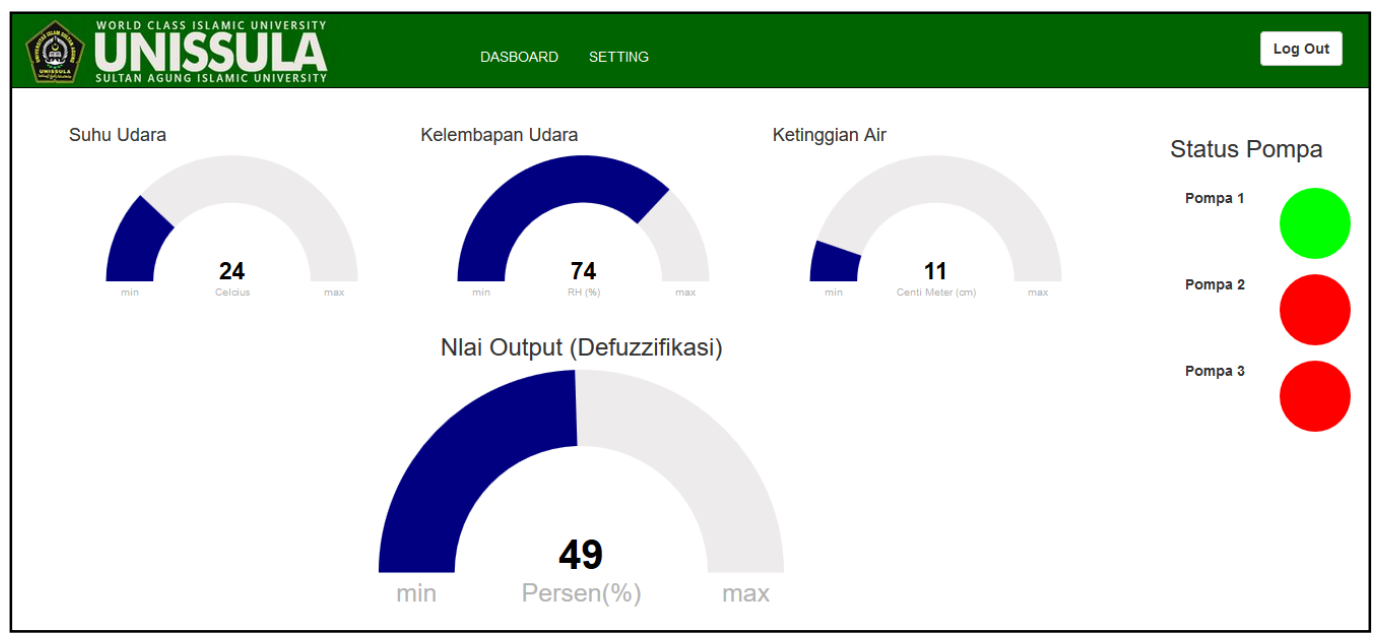

Gambar 6. Tampilan Sistem IoT 
Pada gambar 6 merupakan tampilan antarmuka dari data masukan data sensor. Pada tampilan ini memberikan informasi tentang suhu dan kelembaban udara, tingkat ketinggian air pada kolam peresapan air, dan juga status pompa yang aktif dan tidak aktif dan nilai defuzzyfikasi dari hasil perhitungan yang telah dibuat. Di sini pengguna juga dapat mengatur jarak minimal, standar, dan maksimal pada kolam peresapan air.

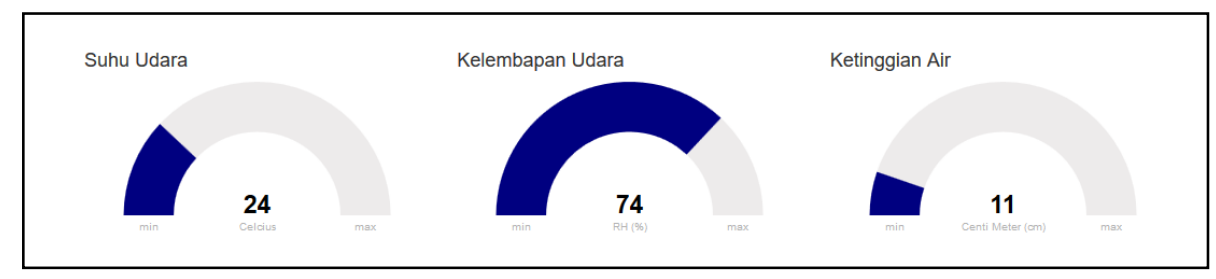

Gambar 7. Tampilan Data Sensor

Pada gambar 7 dapat dilihat menunjukan tampilan nilai variabel input yang akan digunakan yaitu suhu $25^{\circ}$ Celcius, kelembaban udara dengan nilai $63 \mathrm{RH}(\%)$, jarak air $2 \mathrm{~cm}$ dari batas minimal. Variabel kelembaban dan suhu diperoleh dari sensor DHT11 dan Variabel jarak diperoleh dari sensor ultrasonik. Ketiga variabel input tersebut akan di tentukan nilai derajat kenggotaanya.

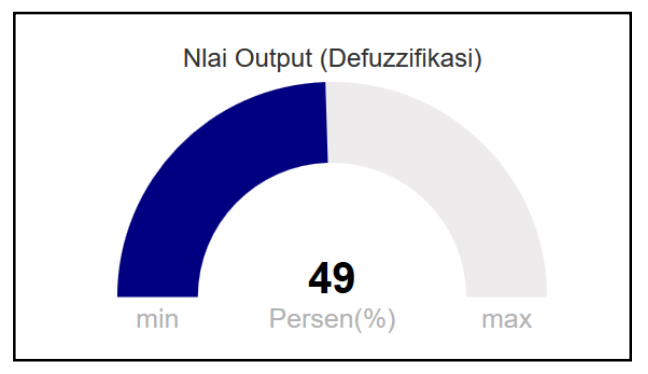

Gambar 8. Tampilan Nilai Defuzzifikasi

Pada gambar 8 dapat dilihat menunjukan tampilan nilai 49 sebagai nilai defuzzifikasi. Untuk memperoleh nilai defuzzifikasi ketiga variabel akan diproses pada rule base dan mesin inferensi. Nilai defuzzifikasi ini yang nantinya akan menjadi acuan untuk menentukan jumlah pompa air yang aktif dan kecepatanya.

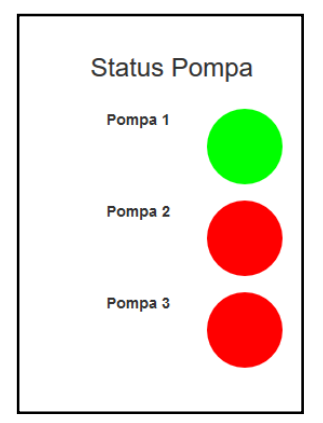

Gambar 9. Tampilan Status Pompa 
Pada gambar 9 dapat dilihat menunjukan tampilan status pompa hanya ada satu pompa yang aktif, jika status indikator pompa bewarna merah berarti status tidak aktif dan indikator akan berubah warna hijau jika pompa aktif.

\section{Kesimpulan}

Pengembangan insfrastruktur berbasis IoT akan memberikan kemudahan dalam pengembangan dan penggunaan fasilitas. Sistem yang dikembangkan guna memperoleh data secara realtime dan kendali pada pompa yang ada pada kolam peresapan air, jumlah pompa dan kecepatan putaran pompa dapat dikontrol secara otomatis sesuai dengan kondisi tingkat ketinggian air kolam, suhu dan kelembapan udara yanng ada pada kolam peresapan air dengan menerapkan kecerdasan buatan Fuzzy Tsukamoto pada IoT. IoT menghadirkan konsep dengan sistem yang terintegrasi agar setiap sistem dapat saling terhubung satu sama lainnya. Dengan demikian, setiap bagian tidak hanya dipermudah dengan sharing data, melainkan akan dipermudah dengan sharing informasi setiap bagian fasilitas.

\section{Referensi}

[1] Ariyani D and Putri R. Sistem Monitoring Banjir Pada Jalan Menggunakan Aplikasi Mobile Dan Modul Wi-Fi. Prosiding SEMNASTEK Fakultas Teknik Universitas Muhammadiyah Jakarta, Jakarta. 2017. Vol.4: 1-8.

[2] Rosyidie A. Banjir: Fakta dan Dampaknya, Serta Penngaruh dari Perubahan Guna Lahan. Journal of Regional and City Planning. 2013; 24(3): 241-249.

[3] Ekajaya F, Hidayat N, and Ananta M. Diagnosis Penyakit THT Menggunakan Metode Fuzzy Tsukamoto Berbasis Android. Jurnal Pengembagan Teknologi Informasi dan Komunikasi Ilmu Komputer. 2018; 2(8): 2361-2365.

[4] Loong K, Sandeep S, and Tschofenig H. Securing the Internet of Things: A Standardization Perspective. IEEE Internet Things Journal. 2014; 1(3): 265-275.

[5] Junaidi A. Internet of Things, Sejarah, Teknologi, Dan Penerapannya : Review. Jurnal Ilmiah Teknologi Infromasi Terapan. 2015; 1(3): 62-66.

[6] Kulkarni G, Gambhir J, and Palwe R, Cloud Computing-Software as Service. Int. J. Cloud Comput. Serv. Sci. 2012; 1(1):11-16.

[7] Syafitri N. Simulasi Sistem Untuk Pengontrolan Conditioner Dengan Menggunakan Logika Fuzzy. Jurnal Informatika. 2016; 10(1): 1164-1172.

[8] Kusumadewi S. Arficial Intelligence (Teknik dan Aplikasinya). Pertama. Yogyakarta: GRAHA ILMU. 2003.

[9] Nazilus M, Alfita R, and Nahari R. Prototype Sistem Monitoring Dan Pengendalian Pintu Air Otomatis Sebagai Peringatan Dini Bahaya Banjir Berbasis Internet Of Things. Seminar Nasional Matematika dan Aplikasinya Universitas Airlangga. Surabaya. 2017: 377-385

[10] Meilina P, Rosanti N, and Nuraeni A. Sistem Pendukung Keputusan Penentuan Jumlah Produksi Barang Dengan Metode Fuzzy Tsukamoto Berbasis Android. Prosiding SEMNASTEK Fakultas Teknik Universitas Muhammadiyah Jakarta, Jakarta. 2017. Vol.4: $1-8$. 